\title{
The effect of the forage-to-concentrate ratio of the partial mixed ration and the quantity of concentrate in an automatic milking system for lactating Holstein cows
}

\author{
S. B. Menajovsky, ${ }^{\star}$ C. E. Walpole,† T. J. DeVries,‡ K. S. Schwartzkopf-Genswein,§ M. E. Walpole,\# \\ and G. B. Penner*1 \\ *Department of Animal and Poultry Science, University of Saskatchewan, Saskatoon, SK, Canada, S7N 5A8 \\ †Large Animal Clinical Sciences, University of Saskatchewan, Saskatoon, SK, Canada, S7N 5B4 \\ †Department of Animal Biosciences, University of Guelph, Guelph, ON, Canada, N1G 2W1 \\ $\S$ Agriculture and Agri-Food Canada, Lethbridge, AB, Canada, T1J 4B1 \\ \#DairySmart Nutrition Group, Crediton, ON, Canada, NOM 1 MO
}

\section{ABSTRACT}

This study was conducted to evaluate the effects of the forage-to-concentrate ratio of the partial mixed ration (PMR) and the quantity of concentrate offered in an automated milking system (AMS), in a feed-first guided-flow barn, on the behavior and performance of dairy cows. Eight ruminally cannulated multiparous Holstein cows were used in a replicated $4 \times 4$ Latin square balanced for carry-over effects. Treatments were arranged in a $2 \times 2$ factorial consisting of a PMR that contained (dry matter basis) either a low (54:46; LFOR) or a high (64:36; H-FOR) forage-to-concentrate ratio and AMS concentrate provision to achieve low (2 $\mathrm{kg} / \mathrm{d}$; L-AMS $)$ or high $(6 \mathrm{~kg} / \mathrm{d}$; H-AMS $)$ intake. Each period consisted of $28 \mathrm{~d}$ with $6 \mathrm{~d}$ for dietary transition, $13 \mathrm{~d}$ for adaptation, and $9 \mathrm{~d}$ of collection. The first 4 $\mathrm{d}$ of data and sample collection were used to evaluate behavioral data (milking frequency, feeding behavior, and standing and lying behavior) and ruminal $\mathrm{pH}$. Subsequently, a sampling device removal day was provided, and the last $4 \mathrm{~d}$ were used to evaluate ruminal fermentation and apparent total-tract digestibility. All $9 \mathrm{~d}$ were used for milk yield measurement, and the 8 $\mathrm{d}$ were used for dry matter intake measurement. Cows fed the H-AMS consumed $3.5 \mathrm{~kg} / \mathrm{d}$ less PMR while consuming $4.2 \mathrm{~kg} / \mathrm{d}$ more AMS concentrate, but total dry matter intake (PMR+AMS) was not affected by treatments averaging $27.3 \mathrm{~kg} / \mathrm{d}$. Although cows fed H-AMS had greater concentrate intake, they also had greater variability for AMS concentrate intake among days ( 0.85 vs. $0.25 \mathrm{~kg} / \mathrm{d}$, respectively). The number of PMR meals and PMR eating behavior were not affected

Received February 28, 2018.

Accepted August 3, 2018.

${ }^{1}$ Corresponding author: greg.penner@usask.ca by the PMR or AMS treatments. Feeding H-AMS did not affect milking frequency averaging 3.63 milkings/d, but tended to increase milk yield by $1.25 \mathrm{~kg} / \mathrm{d}$ relative to L-AMS. Likewise, cows fed the L-FOR tended to have greater milk yield relative to H-FOR (39.3 vs 37.9 $\mathrm{kg} / \mathrm{d}$, respectively), but had greater holding area time. Minimum ruminal $\mathrm{pH}$ tended to be lower for cows fed L-FOR compared with cows fed H-FOR but was not affected by the AMS concentrate treatment. When fed the L-FOR, feeding the H-AMS increased total shortchain fatty acid concentration in the rumen relative to cows fed L-AMS, whereas the response for H-FOR was not affected by the AMS concentrate. These data suggest that feeding H-AMS may improve milk yield, but also increases the day-to-day variability in AMS concentrate consumption. Feeding a L-FOR PMR may increase milk yield without affecting variability in AMS concentrate consumption; however, it may reduce ruminal $\mathrm{pH}$ and increase the time spent in the holding area compared with cows fed a H-FOR PMR.

Key words: automatic milking system, concentrate, partial mixed ration, ruminal fermentation

\section{INTRODUCTION}

Feeding management for cows milked using an automated milking system (AMS) differs from conventional parlor-milked cows, as they are provided a partial mixed ration (PMR) at a feed bunk (or pasture), and a concentrate supplement while in the AMS. Previous research has suggested that provision of concentrate in an AMS is a motivating factor encouraging cows to voluntarily enter the AMS (Prescott et al., 1998; Melin et al., 2005; Bava et al., 2012). As a result, the concept of using concentrate to attract cows to the AMS, coupled with the ability to provide differing quantities of concentrate for individual cows, has resulted in AMS manufacturers suggesting that concentrate quantity 
can be used to minimize fetching and allow for precision feeding (Rodenburg, 2011; Bach and Cabrera, 2017). Producers have apparently implemented these strategies, and in some cases, provide large quantities of concentrate (up to $11.3 \mathrm{~kg} /$ cow per day on an as-fed basis; Salfer and Endres, 2014). Based on a large-scale study, Tremblay et al. (2016) reported a mean AMS concentrate provision of $5.07 \mathrm{~kg} / \mathrm{d}$, with a standard deviation of $1.75 \mathrm{~kg} / \mathrm{d}$. The data presented above collectively indicate that concentrate provision among farms and within farms can be both high and variable.

Despite the variable quantity of concentrate provided in the AMS among herds and among cows, little evidence supports that increasing the quantity of concentrate provided in the AMS improves production outcomes. For example, Halachmi et al. (2005) reported no differences in milking frequency when cows were provided either $1.2 \mathrm{~kg}$ of concentrate/milking or $7 \mathrm{~kg} / \mathrm{d}$. Migliorati et al. (2005) and Bach et al. (2007) reported no improvement in milking frequency or milk yield with increasing AMS concentrate allocation. Additionally, Tremblay et al. (2016) reported a negative association between milk production/cow and the quantity of concentrate $/ 100 \mathrm{~kg}$ of milk provided in the AMS, and Hare et al. (2018) reported that a low quantity (0.5 vs. $5.0 \mathrm{~kg}$ ) of concentrate in the AMS, when isocaloric diets (PMR and AMS concentrate) were fed, tended to improve milk production responses.

Explanations for why additional concentrate in the AMS does not increase milk yield have not been well established. One potential explanation is that the deviation in the quantity of concentrate eligible relative to that delivered increases as the total quantity of concentrate eligible increases (Tremblay et al., 2016). Thus, while cows have more concentrate potentially available, the quantity delivered lags behind due to infrequent milking events, the rate and constraints for concentrate provision, and the maximum meal size imposed by the AMS. The previously stated outcome has been highlighted by Bach et al. (2007) where they targeted 3 or $8 \mathrm{~kg} / \mathrm{d}$ of concentrate, with cows consuming 2.6 or 6.9 $\mathrm{kg} / \mathrm{d}$ (DM basis), respectively, and by Halachmi et al. (2005), where they targeted $1.2 \mathrm{~kg} /$ visit or $7 \mathrm{~kg} / \mathrm{d}$ of concentrate, resulting in an actual consumption of 3.85 and $5.2 \mathrm{~kg} / \mathrm{d}$, respectively. Thus, the diet consumed could be substantially different than the diet formulated. Another potential explanation may be that the AMS allocation also affects consumption of the PMR. Unfortunately, most previous studies have not reported PMR composition or intake (Halachmi et al., 2005; Migliorati et al., 2005; Tremblay et al., 2016). That said, Bach et al. (2007) reported that for every 1-kg increase in AMS concentrate consumed, cows decreased PMR intake by $1.14 \mathrm{~kg}$, demonstrating an inadvertent con- sequence of providing more concentrate in the AMS. A more recent study noted a $1.58-\mathrm{kg}$ reduction in PMR intake for every 1-kg increase in AMS concentrate (DM basis; Hare et al., 2018). The substitution of PMR for AMS concentrate warrants further investigation into feeding management when considering the whole diet.

Both the AMS concentrate and the PMR contribute to meeting the nutrient requirements of dairy cattle. Depending on the quantity of concentrate provided in the AMS, it can be surmised that the PMR could account for at least $60 \%$ of the total dietary DM supply (Salfer and Endres, 2014) and may, in some situations, provide as much as $98 \%$ of the dietary DM (Hare et al., 2018). Although the knowledge regarding AMS concentrate feeding strategies is increasing, little value can be obtained without understanding corresponding changes in PMR composition and PMR intake. To our knowledge, no studies have evaluated how PMR formulation strategies, independent of the AMS concentrate, may affect production responses for cows milked using AMS.

Based on the information presented above, we hypothesized that cows provided with less concentrate in the AMS will have greater PMR intake, milk and milk component yields, and more stable ruminal fermentation than cows offered more concentrate in the AMS. We further hypothesized that decreasing the forage-toconcentrate ratio $(\mathbf{F}: \mathbf{C})$ of the PMR would increase milk yield without negatively affecting voluntary attendance to the AMS, AMS concentrate intake, and would increase the reduction in PMR intake arising from increased AMS concentrate intake.

\section{MATERIALS AND METHODS}

\section{Experimental Design}

This study was conducted at the Rayner Dairy Research and Teaching Facility at the University of Saskatchewan (Saskatoon, Saskatchewan, Canada). All procedures were pre-approved by the University of Saskatchewan Research Ethics Board (protocol 20100021). Eight second-lactation Holstein cows were fitted with a 9-cm ruminal cannula (Robyn Williams, Melbourne, Victoria, Australia) and assigned to 1 of 2 squares based on DIM. At the start of the study the average $\pm \mathrm{SD}$ for DIM, BW, and milk yield were $141 \pm 13.6$ DIM, $685 \pm 29.9 \mathrm{~kg}$, and $47.0 \pm 3.74 \mathrm{~kg}$ for square 1 , respectively, and $169 \pm 9.7 \mathrm{DIM}, 708 \pm 70 \mathrm{~kg}$, and 41.5 $\pm 8.35 \mathrm{~kg}$ for square 2, respectively. Each of the $4 \times 4$ Latin squares were balanced for carry-over effects and differed in the treatment sequence.

Treatments were arranged in a $2 \times 2$ factorial design consisting of a PMR with a low (L-FOR) or high (H-FOR) F:C and either a low $(2 \mathrm{~kg} / \mathrm{d}$ on a DM ba- 
sis; L-AMS) or high AMS (6 kg/d on a DM basis; H-AMS) concentrate target. The AMS concentrate target represented 7.12 and $21.35 \%$ of the total diet, respectively (Table 1 ). The L-FOR PMR contained a $\mathrm{F}: \mathrm{C}$ ratio of 54:46 compared with a ratio of $64: 36$ for the H-FOR PMR. All PMR were adjusted to 50\% DM by adding water at the time of mixing. The PMR was provided in Insentec (Hokofarm Group, Marknesse, the Netherlands) feed bunks, to which cows were individually trained to consume from their own bunk. Daily PMR provision was distributed among 2 feedings: $60 \%$ of the daily allocation was offered at $1000 \mathrm{~h}$ and $40 \%$ offered at $2200 \mathrm{~h}$.

All dietary ingredients were common among treatments, as the pellet provided in the AMS was the same pellet that was used in the PMR (Table 1). Diets were formulated to be balanced for macro- and micronutrient supply and had ME and protein allowable milk yield predictions that were similar based on the Nutritional Dynamic System (RUM\&N Sas, Reggio Emilia, Italy). Predicted total intake (28 kg of DM), cow BW, and pre-study milk yield and composition were used to formulate the diets. To ensure that the targeted F:C ratio of the PMR was achieved throughout the experiment, samples of forages (barley silage, corn silage, and grass hay) were collected twice weekly and concentrate samples were collected once weekly. Samples were used to determine the DM concentration by placing them in a forced air oven at $55^{\circ} \mathrm{C}$ until achieving a constant weight. The AMS was calibrated once weekly with the calibration procedure conducted in triplicate. To ensure the amount of AMS concentrate targeted was achieved for each treatment, the eligible quantity available exceeded the target quantity. Thus, to achieve 2 and 6 $\mathrm{kg} / \mathrm{d}$ of concentrate (DM basis), a total of 2.07 and 6.55 $\mathrm{kg} / \mathrm{d}$ was eligible.

Each period of the Latin square consisted of $28 \mathrm{~d}$. The first $6 \mathrm{~d}$ of each period were used to transition cows to their respective diet followed by a 13-d diet adaptation. The last $9 \mathrm{~d}$ were used for data and sample collection. The diet transition was accomplished by providing 25,50 , and $75 \%$ of the final diet starting on

Table 1. Ingredient composition, chemical composition, and particle size distribution of the partial mixed ration (PMR) for treatments that consisted of a forage-to-concentrate ratio of the PMR of 54:46 (L-FOR) or forage-to-concentrate ratio of the PMR of 64:36 (H-FOR) in combination with a 2 (L-AMS) or 6 (H-AMS) kg/d of automated milking system (AMS) concentrate allocation

\begin{tabular}{|c|c|c|c|c|}
\hline \multirow[b]{2}{*}{ Item } & \multicolumn{2}{|c|}{ L-FOR } & \multicolumn{2}{|c|}{ H-FOR } \\
\hline & H-AMS & L-AMS & H-AMS & L-AMS \\
\hline Barley silage & 16.55 & 19.57 & 19.57 & 23.13 \\
\hline Corn silage & 10.50 & 12.46 & 12.46 & 14.70 \\
\hline Alfalfa hay & 15.02 & 17.79 & 17.79 & 21.07 \\
\hline Barley grain & 26.62 & 18.86 & 18.86 & 9.79 \\
\hline Palmitic acid ${ }^{2}$ & 0.71 & 0.71 & 0.71 & 0.71 \\
\hline \multicolumn{5}{|l|}{ Chemical composition $^{3}$} \\
\hline $\mathrm{OM}, \%$ of DM & $92.76 \pm 0.17$ & $92.27 \pm 0.18$ & $92.30 \pm 0.20$ & $91.74 \pm 0.21$ \\
\hline $\mathrm{CP}, \%$ of $\mathrm{DM}$ & $16.27 \pm 0.11$ & $16.55 \pm 0.14$ & $16.41 \pm 0.10$ & $16.72 \pm 0.14$ \\
\hline aNDFom, $\%$ of DM & $27.65 \pm 0.41$ & $29.54 \pm 0.46$ & $29.40 \pm 0.38$ & $31.58 \pm 0.44$ \\
\hline $\mathrm{ADF}, \%$ of DM & $17.57 \pm 0.10$ & $19.28 \pm 0.06$ & $19.24 \pm 0.09$ & $21.24 \pm 0.07$ \\
\hline Starch, \% of DM & $33.86 \pm 0.76$ & $30.21 \pm 0.55$ & $30.43 \pm 0.66$ & $26.18 \pm 0.51$ \\
\hline \multicolumn{5}{|c|}{ Particle size distribution of the $\mathrm{PMR}^{4}$} \\
\hline $4 \mathrm{~mm}, \%$ & $51.96 \pm 1.46$ & $48.95 \pm 3.07$ & $44.35 \pm 1.51$ & $41.41 \pm 3.12$ \\
\hline Pan, \% & $18.15 \pm 1.33$ & $21.08 \pm 2.96$ & $20.35 \pm 1.37$ & $23.27 \pm 2.99$ \\
\hline
\end{tabular}

${ }^{1}$ The pellet provided in the AMS (AMS supplement) was the same pellet used in the PMR (PMR supplement) and contained $24.3 \%$ barley grain, $27.9 \%$ canola meal, $10.4 \%$ corn grain, $10.1 \%$ soybean meal, $6.2 \%$ peas, $2.1 \%$ corn dried distillers grains with solubles, $4.10 \%$ wheat, $2.0 \%$ corn gluten meal, 2.2\% palmitic acid (Energizer RP10, Scothorn Nutrition, Grand Pré, NS, Canada), 1.0\% Acid Buf (Celtic Sea Minerals, Cork, Ireland), $1.6 \%$ sodium bicarbonate, $0.11 \%$ calcium phosphate mono, $2.5 \%$ ground limestone, $1.8 \%$ tallow, $2.8 \%$ premix, and $0.9 \%$ salt white. Premix contained 3.7\% sulfur, 5.55\% vitamin D (2,280 IU/g), 2.72\% Sel Plex 1000 (Alltech, Calgary, AB, Canada), $42.67 \%$ magnesium sulfate $7 \mathrm{H}_{2} \mathrm{O}, 3.70 \%$ vitamin A $(12,500,000 \mathrm{IU} / \mathrm{kg}), 1.26 \% \mathrm{Zn}, 0.56 \%$ vitamin $\mathrm{E}(500,000 \mathrm{IU} / \mathrm{kg}), 0.37 \%$ biotin $(20,000 \mathrm{~g} / \mathrm{kg}), 1.26 \% \mathrm{Mn}, 0.64 \% \mathrm{Cu}$, $37.01 \%$ wheat middlings, $0.56 \%$ chromium propionate, and $0.01 \%$ ethylenediamine dihydroiodide.

${ }^{2}$ Energizer RP10 (Scothorn Nutrition, Grand Pre, NS, Canada).

${ }^{3}$ Period composites were analyzed, and values indicate the mean \pm SEM. Water was added to the PMR to achieve a final DM concentration of $50 \%$. aNDFom $=$ neutral detergent fiber analyzed using $\alpha$-amylase and sodium sulfite and corrected for ash content.

${ }^{4}$ Values indicate the mean \pm SEM of the period composites. 
d 1,3 , and 5, with cows receiving $100 \%$ of their final diet on $\mathrm{d} 7$. The 9 -d sampling period was divided into two 4 -d phases with $1 \mathrm{~d}$ of rest interspacing the two 4-d measurement protocols. The first $4 \mathrm{~d}$ were used to evaluate behavioral responses, whereas the second $4 \mathrm{~d}$ were used to evaluate metabolic responses.

Throughout the study, cows were housed in a pen with 12 freestalls bedded with chopped straw over mattresses (Eva Cow Mats, BSM Canarm, Ontario, Canada). The freestall area was divided by a 1-way gate that cows passed through to enter the feed bunk area. To leave the feed bunk area, cows passed through a selection gate that either directed them to the holding area for the AMS (De Laval International, Tumba, Sweden), or directed them back to the freestall area. Cows were granted access to the AMS when the time since the last visit exceeded $4 \mathrm{~h}$ or the predicted milk yield exceeded $9 \mathrm{~kg}$. The AMS concentrate allocation at each milking was based on a linear accrual over time with a minimum concentrate provision of $50 \mathrm{~g}$ and a maximum of $2.50 \mathrm{~kg}$. Water was available ad libitum in the freestall area.

\section{$B W$ and BCS}

Cow BW was measured at the start and at the end of each period on 2 consecutive days and the average BW was calculated. Body condition score was assessed independently by 3 trained observers using a 5 -point scale according to Wildman et al. (1982) on d 1 of each experimental period. The average BCS was calculated and used for data analysis.

\section{DMI, Feeding Behavior, and PMR Sorting Behavior}

The amounts of PMR offered and refused (as-fed basis) were recorded daily. Cows were fed the PMR ad libitum targeting a 5 to $10 \%$ refusal rate on an as-fed basis. In addition, the amount of concentrate offered in the AMS was recorded daily by the AMS software. The PMR and AMS concentrate consumed were summed to determine total intake. During each of the 4-d sampling periods, feed ingredient samples were collected daily (1 $\mathrm{kg}$ for forages and $500 \mathrm{~g}$ for concentrates), composited on an equal weight basis, and stored in a freezer $\left(-20^{\circ} \mathrm{C}\right)$ until analysis. Composited feed ingredients were mixed thoroughly, and a representative sample was used for DM determination in duplicate. To determine DM, samples were placed in a forced-air oven and held at $55^{\circ} \mathrm{C}$ until achieving a constant weight. A representative sample of the PMR refusals (20\% of the refusal weight) from each the 4-d behavioral and 4-d metabolic collection phases was collected daily. Refusal samples from an individual cow were composited proportionally and stored at $-20^{\circ} \mathrm{C}$. The refusal samples collected during the behavioral measurement phase were used for DM and particle size separation (described below), and refusal samples collected during the metabolic measurement period were used for DM determination and chemical analysis (described below). Dry matter intake of the PMR and the AMS were determined separately by summing the respective DMI of each of the 4-d sampling periods. The substitution rate was calculated as described by Bargo et al. (2003) with the exception that PMR intake was used instead of pasture intake.

Feeding behavior for the PMR was determined for each cow during the 4-d behavioral collection phase using the software associated with the automated feed bunks (Roughage Intake Control System, Insentec, Marknesse, the Netherlands). Feed bunks were recalibrated when the empty feed bunk weight deviated by $\pm 0.2 \mathrm{~kg}$. The method used to determine feeding behavior has been described by Chapinal et al. (2007). A meal criterion for each cow in each period was determined, as reported by DeVries et al. (2003), with an average of $44.10 \pm 49.48$ min (mean \pm SD).

Particle size distribution of the PMR and refusals were determined using the Penn State Particle Size Separator (Nasco, Modesto, CA) as described by Kononoff et al. (2003) except that the aperture openings were 19,8 , and $4 \mathrm{~mm}$, along with a bottom pan (Maulfair et al., 2011). Each composite sample was measured in duplicate. After particle size separation, the sorting index was calculated as described by Leonardi and Armentano (2003). Values equal to $100 \%$ indicate no sorting, values $<100 \%$ indicate sorting against a specific particle size, and values $>100 \%$ indicate sorting for a specific particle size.

The dried feed and refusal samples collected during the metabolic collection phase were ground to pass through a 1-mm sieve using a hammer mill (Christy and Norris, Christy Turner Ltd., Chelmsford, UK). Ground samples were sent to Cumberland Valley Analytical Services (Hagerstown, MD) and analyzed for [DM, OM, CP, NDF measured using $\alpha$-amylase and sodium sulfite followed by correction for the ash content, ADF, starch, ether extract, and undigested NDF (uNDF)] following $240 \mathrm{~h}$ of in vitro fermentation. The NDF was analyzed using amylase and sodium sulfite and corrected for ash content.

\section{Milk and Milk Component Yield, Milking Activity, and Standing and Lying Time}

Milk yield was recorded at each milking by the AMS. During the 9-d collection period, milk samples were 
collected from each cow $(20 \mathrm{~mL})$ using an automated sampling device. Samples were preserved with potassium dichromate and stored at $4^{\circ} \mathrm{C}$. Milk samples were then mixed and composited proportionally based on the yield at each milking to form a daily composite sample of $40 \mathrm{~mL}$. The daily composite samples for each cow were analyzed for CP, fat, lactose, MUN, and SCC at the Dairy Herd Improvement Laboratory (Edmonton, $\mathrm{AB}$, Canada). Daily milk and milk component yields were subsequently calculated.

In addition, the AMS recorded the number of visits for each cow to the AMS (milking frequency), time of milking, kick-offs during milking, incomplete milking events, and the time and date that cows passed through selection gates. These data were used to calculate milking duration, inter-milking intervals, incidence of kickoffs during milking, and incomplete milking events. These data were also used to calculate the amount of time spent in the holding area before milking along with the number of times cows passed through the sort gates but were not provided permission to enter the holding pen.

The lying time, standing time, and lying and standing bouts were measured during the behavioral phase (d 20 to 24) using accelerometers (HOBO Pendant G Acceleration Data Loggers, Onset Computer Corp., Bourne, MA) that were attached horizontally to the left hind leg of each cow, using a flexible bandage, on d 19 of each experimental period. The loggers were set to record the position of the leg every $30 \mathrm{~s}$ (Ledgerwood et al., 2010). After removal, the measurements were used to calculate total daily standing and lying time $(\mathrm{min} / \mathrm{d})$, the frequency of each bout (no./d), and their duration (min/bout) for the experimental period according to Zobel and Chapinal (2013).

\section{Ruminal Fermentation}

Ruminal $\mathrm{pH}$ was measured during the behavioral period (d 20 to 24) using the Lethbridge Research Centre Ruminal pH Measurement System (LRCpH, Dascor, Escondido, CA) as described by Penner et al. (2006). The indwelling $\mathrm{pH}$ systems were standardized in $\mathrm{pH}$ buffer solutions 7 and 4 (Fisher Chemical, Ottawa, ON, Canada) at $39^{\circ} \mathrm{C}$, and set to record $\mathrm{mV}$ values every 5 min. The $\mathrm{pH}$ systems were inserted in the ventral sac of the rumen on d 19 of each experimental period and were maintained in the ventral sac using two $1-\mathrm{kg}$ weights attached to the electrode shroud. Although inserted on d 19, only data obtained from d 20 to 24 of each experimental period were used enabling data collection for 4 complete days. Upon removal from the rumen, the $\mathrm{pH}$ systems were cleaned, standardized, and the data were downloaded. Data from the starting and ending standardizations were used to derive 2 linear relationships between $\mathrm{mV}$ readings and $\mathrm{pH}$. Using the linear relationships, the $\mathrm{mV}$ data were converted to $\mathrm{pH}$ values using a linear offset between the starting and ending slopes and intercepts. The daily ruminal $\mathrm{pH}$ values were then summarized as minimum, mean, and maximum $\mathrm{pH}$ for each cow. The duration and area that ruminal $\mathrm{pH}$ was below 5.8 were calculated according to Penner et al. (2007).

During the last $4 \mathrm{~d}$ of each experimental period (d 25 to 28), samples of ruminal digesta and feces were collected every 12 h over a 96 -h period, with a 3 -h offset between days such that the final combined composite (8 samples) was representative of a 24 -h cycle. For ruminal fluid, $250 \mathrm{~mL}$ of mixed digesta each from the cranial, ventral, and caudal sac of the rumen was collected and combined. The digesta was then strained through 2 layers of cheesecloth, and $10 \mathrm{~mL}$ of the strained ruminal fluid was added to a tube containing $2 \mathrm{~mL}$ of $25 \%$ (wt/ vol) meta-phosphoric acid and analyzed for short-chain fatty acid (SCFA) concentrations. An additional 10-mL sample was added to $2 \mathrm{~mL}$ of sulfuric acid for analysis of $\mathrm{NH}_{3}-\mathrm{N}$. Samples were placed on ice until being stored at $-20^{\circ} \mathrm{C}$. Short-chain fatty acid concentrations were determined according to Khorasani et al. (1996) and $\mathrm{NH}_{3}-\mathrm{N}$ was determined according to Fawcett and Scott (1960).

At each fecal sampling time, a minimum of $200 \mathrm{~g}$ of feces were collected directly from the rectum. Subsequently, $125 \mathrm{~g}$ of the collected fecal sample from each sampling point was used to prepare a composite and was stored at $-20^{\circ} \mathrm{C}$. Duplicate samples $(500 \mathrm{~g})$ of feces were dried in a forced-air oven at $55^{\circ} \mathrm{C}$ to determine DM concentration. Fecal samples were ground and sent to Cumberland Valley Analytical Services (Hagerstown, MD) for chemical analysis as previously described. The concentrations of uNDF in the feed, refusals, and fecal samples were used to determine uNDF intake to enable prediction of fecal output and apparent total-tract digestibility (Huhtanen et al., 1994).

\section{Statistical Analysis}

Data were analyzed as a replicated $4 \times 4$ Latin square with a $2 \times 2$ factorial treatment arrangement using the MIXED procedure of SAS (9.4, SAS Institute Inc., Cary, NC). The model included the fixed effects of square, period, PMR, AMS, and the interaction of $\mathrm{PMR} \times \mathrm{AMS}$, and the random effect of cow nested in square. For variables that incorporated repeated measures (AMS concentrate and PMR intake), day was included in the model and covariance error structures 
Table 2. Effect of feeding a forage-to-concentrate ratio of the partial mixed ration (PMR) of 54:46 (L-FOR) or forage-to-concentrate ratio of the PMR of 64:36 (H-FOR) in combination with a 2 (L-AMS) or 6 (H-AMS) kg/d of automated milking system (AMS) concentrate allocation on BW, BCS, DMI, behavior associated with PMR intake, PMR sorting behavior, and AMS intake

\begin{tabular}{|c|c|c|c|c|c|c|c|c|}
\hline Variable & \multicolumn{2}{|c|}{ L-FOR } & \multicolumn{2}{|c|}{ H-FOR } & $\mathrm{SEM}^{1}$ & \multicolumn{3}{|c|}{$P$-value } \\
\hline $\mathrm{BW}, \mathrm{kg}$ & 707 & 710 & 706 & 705 & 19.5 & 0.45 & 0.80 & 0.56 \\
\hline Total DMI, ${ }^{3} \mathrm{~kg} / \mathrm{d}$ & 27.2 & 27.7 & 26.7 & 27.5 & 0.86 & 0.46 & 0.18 & 0.68 \\
\hline \multicolumn{9}{|l|}{ PMR eating characteristic } \\
\hline PMR DMI, kg/d & 25.2 & 21.6 & 24.6 & 21.3 & 0.8 & 0.39 & $<0.01$ & 0.85 \\
\hline Daily SD, $\mathrm{kg} / \mathrm{d}$ & 1.70 & 1.58 & 2.05 & 1.71 & 0.28 & 0.21 & 0.22 & 0.55 \\
\hline Meals, no./d & 6.22 & 5.59 & 5.94 & 5.60 & 0.72 & 0.80 & 0.37 & 0.78 \\
\hline Meal size, $\mathrm{kg}$ of $\mathrm{DM} /$ meal & 4.07 & 4.17 & 4.15 & 3.84 & 0.54 & 0.78 & 0.81 & 0.65 \\
\hline Eating rate, $\mathrm{kg}$ of $\mathrm{DM} / \mathrm{min}$ & 0.10 & 0.11 & 0.11 & 0.09 & 0.01 & 0.66 & 0.77 & 0.20 \\
\hline Inter-meal interval, min & 207.2 & 233.2 & 214.8 & 230.1 & 24.65 & 0.90 & 0.26 & 0.77 \\
\hline Eating time, $\mathrm{min} / \mathrm{meal}$ & 34.79 & 35.64 & 38.28 & 36.84 & 5.02 & 0.57 & 0.94 & 0.78 \\
\hline Eating time, $\min / \mathrm{d}$ & 198.77 & 174.11 & 212.01 & 180.37 & 11.42 & 0.26 & $<0.01$ & 0.68 \\
\hline \multicolumn{9}{|l|}{ AMS eating characteristic } \\
\hline AMS DMI, kg/d & 2.04 & 6.09 & 2.03 & 6.27 & 0.22 & 0.65 & $<0.01$ & 0.59 \\
\hline Minimum AMS intake, $\mathrm{kg} / \mathrm{d}$ & 1.69 & 4.71 & 1.61 & 5.01 & 0.27 & 0.60 & $<0.01$ & 0.37 \\
\hline Maximum AMS intake, $\mathrm{kg} / \mathrm{d}$ & 2.41 & 7.25 & 2.36 & 7.49 & 0.21 & 0.62 & $<0.01$ & 0.47 \\
\hline Daily $\mathrm{SD}, \mathrm{kg} / \mathrm{d}$ & 0.23 & 0.84 & 0.27 & 0.86 & 0.07 & 0.64 & $<0.01$ & 0.86 \\
\hline
\end{tabular}

${ }^{\mathrm{z}}$ Indicates that means differ from $100 \%$ using a 2-tailed $t$-test.

${ }^{1} \mathrm{SEM}$ for the interaction is reported.

${ }^{2}$ BCS was assessed using a 5-point scale according to Wildman et al. (1982).

${ }^{3}$ Total DMI was calculated as the sum of PMR intake and the AMS intake.

${ }^{4}$ The sorting index was calculated as described by Leonardi and Armentano (2003).

were tested. The covariance error structure for each variable that yielded the lowest Akaike's information criterion and Bayesian information criterion was used. When the F-test for the interaction was significant, means were separated and analyzed using a Bonferroni mean separation test. To determine whether the means for sorting index analyses were different from $100 \%$, a 2 -tailed $t$-test analysis was used. Statistical significance was declared when $P \leq 0.05$ and tendencies are discussed when $0.10 \geq P>0.05$.

\section{RESULTS}

\section{BW, BCS, DMI, PMR, and AMS Intake}

Cow BW and BCS did not differ among treatments (Table 2). In addition, total DMI (PMR + AMS) was not affected by PMR or AMS treatments with an average DMI of $27.3 \mathrm{~kg} / \mathrm{d}$. Although PMR intake was not affected by the $\mathrm{F}: \mathrm{C}$ ratio of the PMR, feeding a greater quantity of concentrate in the AMS reduced PMR intake $(24.9$ vs. $21.4 \mathrm{~kg} / \mathrm{d} ; P<0.01)$. As a result, for every $1-\mathrm{kg}$ increase in concentrate allocation in the
AMS, cows decreased PMR intake by $0.83 \mathrm{~kg}$ (DM basis). The number of PMR meals/day, meal size, eating rate, and inter-meal interval were not affected by the amount of concentrate offered in the AMS or by the F:C ratio of the PMR $(P>0.10)$. Partial mixed ration eating time ( $\mathrm{min} / \mathrm{meal})$ was not affected, but total PMR eating time was greater when cows were fed the L-AMS compared with cows fed the H-AMS (205.39 vs. $177.24 \mathrm{~min} / \mathrm{d} ; P<0.01)$. Cows consuming L-FOR selected against particles retained on the 8 -mm sieve of the Penn State Particle Size Separator to a greater extent than cows consuming H-FOR (97.41 vs. $98.94 \%$; $P$ $=0.02)$. In addition, cows offered the H-AMS selected against particles retained on the 8 -mm sieve $(P<0.01)$ and selected for particles retained on the $4-\mathrm{mm}$ sieve $(P<0.01)$ to a greater extent than cows fed L-AMS.

The F:C ratio of the PMR did not affect AMS concentrate intake $(P=0.65$; Table 2$)$; however, by design, H-AMS cows consumed more $(6.18$ vs. $2.04 \mathrm{~kg})$ than L-AMS cows $(P<0.01)$. Although the offered levels of concentrate in the AMS were as targeted (6 and $2 \mathrm{~kg}$ for H-AMS and L-AMS, respectively), the amount of concentrate that was potentially available for delivery 
in the AMS exceeded the amount offered as a requirement to ensure target AMS concentrate delivery was achieved. As a result, greater variability in daily AMS concentrate consumption was observed when cows were provided H-AMS compared with L-AMS ( 0.85 vs. 0.25 $\mathrm{kg} / \mathrm{d} ; P<0.01)$.

\section{Milking Frequency, Milk and Milk Component Yield, and Milking Behavior in the AMS}

Milking frequency was not affected by the $\mathrm{F}: \mathrm{C}$ ratio of the PMR or by the amount of concentrate provided in the AMS (Table 3). In addition, no differences were observed for milk yield/milking, milking duration/ milking, or inter-milking interval. The percentage of milkings that the milker was kicked off, and percentage of incomplete milkings did not differ among treatments. However, daily milk yield tended to be greater for cows fed L-FOR than H-FOR $(39.3 \mathrm{~kg} / \mathrm{d}$ vs. $37.9 \mathrm{~kg} / \mathrm{d} ; P$ $=0.10)$ and tended to be greater when fed H-AMS compared with L-AMS $(39.2 \mathrm{~kg} / \mathrm{d}$ vs. $38.0 \mathrm{~kg} / \mathrm{d} ; P=$ $0.10)$. Crude protein yield followed the same pattern as daily milk yield, whereas fat yield was not affected by the AMS or PMR treatments. Crude protein concentration was not affected by the $\mathrm{F}: \mathrm{C}$ ratio of the PMR, but it was greater for cows fed H-AMS than L-AMS (3.24 vs. $3.20 \% ; P=0.04)$. Milk fat concentration was not affected by the $\mathrm{F}: \mathrm{C}$ ratio of the PMR, but tended to be greater for cows fed L-AMS than H-AMS (3.63 vs. $3.51 \% ; P=0.09$ ). For MUN, cows provided H-FOR had greater MUN than cows provided L-FOR $(P<$ 0.01 ) and cows provided L-AMS had greater MUN than those fed H-AMS $(P=0.02)$.

\section{Ruminal Fermentation}

Minimum $\mathrm{pH}$ tended to be greater for H-FOR than L-FOR $(P=0.09$; Table 4$)$, but mean and maximum $\mathrm{pH}$ did not differ. Cows fed H-AMS did not differ from cows fed L-AMS for minimum, mean, or maximum ruminal $\mathrm{pH}$. The duration that $\mathrm{pH}$ was $<5.8$ was not affected by $\mathrm{F}: \mathrm{C}$ ratio of the PMR or quantity of AMS concentrate. However, cows fed L-FOR tended to have greater area that $\mathrm{pH}$ was $<5.8$ than cows fed H-FOR $(P=0.07)$.

When fed a L-FOR diet, feeding H-AMS increased total SCFA concentration relative to L-AMS, but no differences were detected for cows fed H-FOR regardless of the quantity of concentrate offered in the AMS $(\mathrm{PMR} \times$ AMS, $P=0.05$; Table 4$)$. Cows fed L-FOR had less acetate and isobutyrate, greater propionate, and tended to have less butyrate as a molar proportion relative to cows fed H-FOR. Whereas the concentration of acetate was less, propionate was greater, and the concentration of isobutyrate, butyrate, isovalerate, and caproate were less for cows fed H-AMS than L-AMS. Neither the F:C ratio of the PMR nor the amount of concentrate provided in the AMS affected ruminal ammonia concentration.

\section{Total-Tract Digestibility}

Digestibility of DM and OM was greater for cows fed L-FOR relative to H-FOR and greater for cows fed H-AMS than L-AMS $(P<0.01$; Table 5$)$. Digestibility of ADF was greater for cows offered H-FOR compared with L-FOR $(P=0.01)$ and was also greater for cows

Table 3. Effect of feeding a forage-to-concentrate ratio of the partial mixed ration (PMR) of 54:46 (L-FOR) or forage-to-concentrate ratio of the PMR of 64:36 (H-FOR) in combination with a 2 (L-AMS) or 6 (H-AMS) kg/d of automated milking system (AMS) concentrate allocation on milking activity, milk, milk component yield, and AMS performance

\begin{tabular}{|c|c|c|c|c|c|c|c|c|}
\hline Variable & \multicolumn{2}{|c|}{ L-FOR } & \multicolumn{2}{|c|}{ H-FOR } & $\mathrm{SEM}^{1}$ & \multicolumn{3}{|c|}{$P$-value } \\
\hline Milking frequency, no./d & 3.66 & 3.66 & 3.47 & 3.72 & 0.16 & 0.41 & 0.11 & 0.11 \\
\hline Milking duration, min/milking & 7.06 & 7.28 & 7.13 & 7.39 & 0.86 & 0.68 & 0.28 & 0.94 \\
\hline Inter-milking interval, min & 390.2 & 389.3 & 411.7 & 376.8 & 19.90 & 0.67 & 0.10 & 0.12 \\
\hline Kick-offs, \% & 8.51 & 7.06 & 13.14 & 8.91 & 5.16 & 0.19 & 0.24 & 0.56 \\
\hline \multicolumn{9}{|l|}{ Yield, kg/d } \\
\hline $\mathrm{CP}$ & 1.23 & 1.30 & 1.19 & 1.24 & 0.07 & 0.10 & 0.07 & 0.74 \\
\hline Fat & 1.36 & 1.36 & 1.38 & 1.35 & 0.07 & 0.93 & 0.76 & 0.54 \\
\hline \multicolumn{9}{|l|}{ Milk composition, $\%$} \\
\hline $\mathrm{CP}$ & 3.21 & 3.25 & 3.19 & 3.24 & 0.05 & 0.47 & 0.04 & 0.97 \\
\hline Fat & 3.57 & 3.46 & 3.70 & 3.55 & 0.17 & 0.11 & 0.09 & 0.78 \\
\hline Lactose & 4.59 & 4.61 & 4.54 & 4.57 & 0.06 & $<0.01$ & 0.04 & 0.44 \\
\hline
\end{tabular}

${ }^{1} \mathrm{SEM}$ for the interaction is reported. 
Table 4. Effect of feeding a forage-to-concentrate ratio of the partial mixed ration (PMR) of 54:46 (L-FOR) or forage-to-concentrate ratio of the PMR of 64:36 (H-FOR) in combination with a 2 (L-AMS) or 6 (H-AMS) kg/d of automated milking system (AMS) concentrate allocation on ruminal fermentation: $\mathrm{pH}$, short-chain fatty acid (SCFA), and ammonia concentration

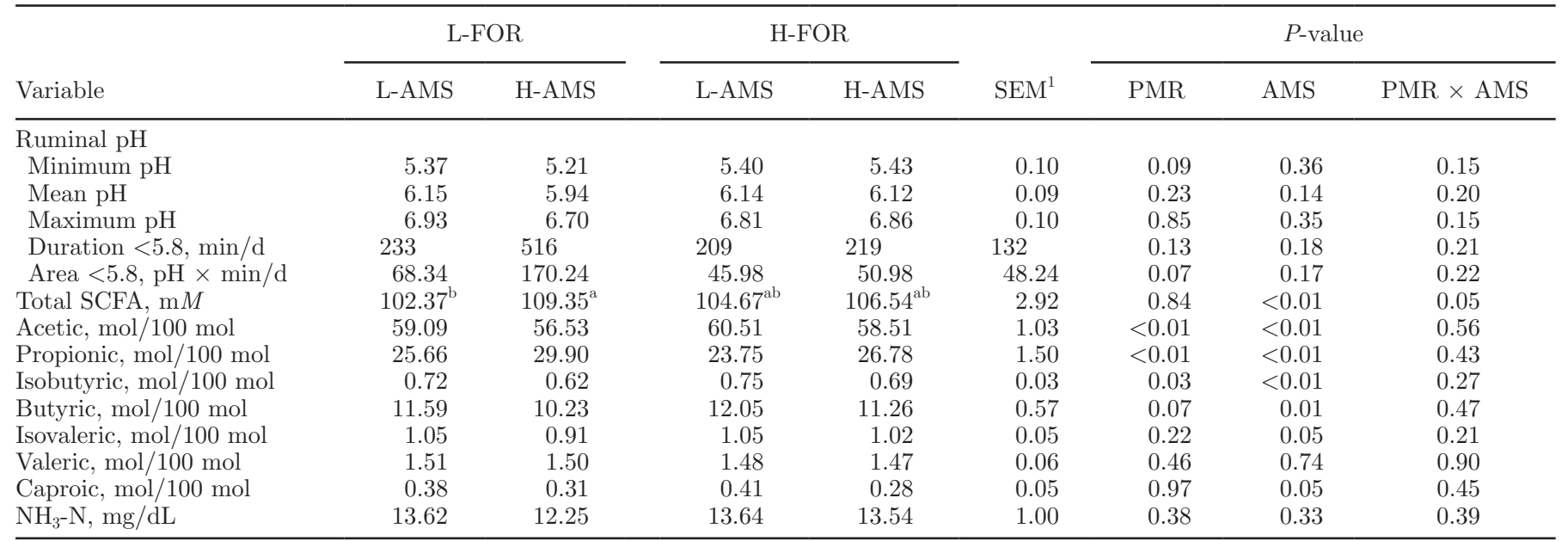

${ }^{\mathrm{a}, \mathrm{b}}$ Means within a row with uncommon superscripts differ $(P<0.05)$.

${ }^{1} \mathrm{SEM}$ for the interaction is reported.

fed L-AMS than H-AMS $(P=0.02)$. Neutral detergent fiber, $\mathrm{CP}$, starch, and ether extract digestibility were not affected by the $\mathrm{F}: \mathrm{C}$ ratio of the PMR or by the amount of AMS concentrate provided.

\section{Activity Budgets: Gate Passing Events, Times in Areas, Lying, and Standing Behavior}

Cows offered H-FOR in combination with H-AMS tended to pass through the selection gate more than cows fed the other treatments $(P=0.08$; Table 6$)$. The number of rejections to the holding area did not differ among treatments, averaging over 5 rejections/d. Cows fed L-FOR spent $32.4 \mathrm{~min} / \mathrm{d}$ more in the holding area than cows fed H-FOR $(P=0.04)$. However, when evaluated as holding area time/visit to the AMS, only a tendency was observed for a greater duration of time in the holding area for cows fed L-FOR relative to cows fed H-FOR $(P=0.06)$. Cows fed H-AMS spent more time in the AMS relative to cows fed L-AMS $(P=$ 0.05 ). In contrast, cows fed L-AMS spent more time consuming the PMR than cows fed H-AMS $(P<0.01)$. Standing and lying behavior were not affected by the amount of concentrate offered in the AMS or by the $\mathrm{F}: \mathrm{C}$ ratio of the $\mathrm{PMR}$.

\section{DISCUSSION}

The focus of this study was to evaluate the effect of the F:C ratio of the PMR, the amount of AMS concentrate offered, and their interaction. The only detected interaction among treatments was for the ruminal SCFA concentration. This interaction suggests that when feeding a L-FOR PMR, increasing the concentrate allocation in the AMS results in detectable increases in the SCFA concentration in the rumen, whereas, with a

Table 5. Effect of feeding a forage-to-concentrate ratio of the partial mixed ration (PMR) of 54:46 (L-FOR) or forage-to-concentrate ratio of the PMR of 64:36 (H-FOR) in combination with a 2 (L-AMS) or 6 (H-AMS) kg/d of automated milking system (AMS) concentrate allocation on total-tract digestibility

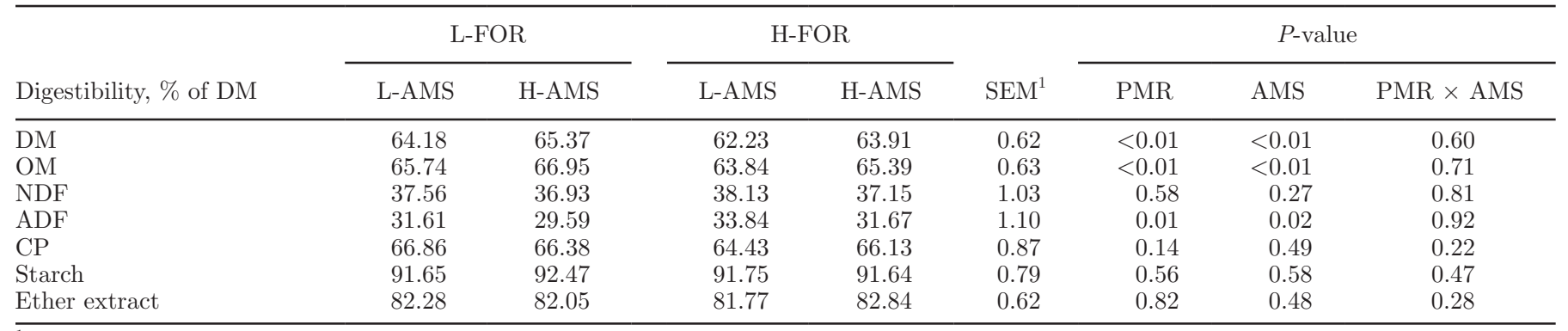

${ }^{1} \mathrm{SEM}$ for the interaction is reported. 
Table 6. Effect of feeding a forage-to-concentrate ratio of the partial mixed ration (PMR) of 54:46 (L-FOR) or forage-to-concentrate ratio of the PMR of 64:36 (H-FOR) in combination with a 2 (L-AMS) or 6 (H-AMS) kg/d of automated milking system (AMS) concentrate allocation on gate passing events, times in areas, and time expenditure for standing and lying

\begin{tabular}{|c|c|c|c|c|c|c|c|c|}
\hline Variable & \multicolumn{2}{|c|}{ L-FOR } & \multicolumn{2}{|c|}{ H-FOR } & $\mathrm{SEM}^{1}$ & \multicolumn{3}{|c|}{$P$-value } \\
\hline Passes through the sort gate, no./d & 8.59 & 8.22 & 7.91 & 10.06 & 0.93 & 0.41 & 0.21 & 0.08 \\
\hline Time in holding area, $\mathrm{min} / \mathrm{d}$ & 124.7 & 101.3 & 85.4 & 75.8 & 20.6 & 0.04 & 0.28 & 0.65 \\
\hline Time in holding area, min/visit & 34.2 & 27.7 & 25.5 & 19.4 & 6.9 & 0.06 & 0.16 & 0.96 \\
\hline Time in AMS, min/d & 25.4 & 26.3 & 24.1 & 27.1 & 2.4 & 0.79 & 0.05 & 0.26 \\
\hline Standing bouts, no./d & 4.38 & 4.80 & 4.75 & 4.77 & 0.46 & 0.60 & 0.51 & 0.53 \\
\hline Mean standing bout duration, $\min /$ bout & 102.7 & 94.3 & 86.9 & 87.1 & 14.6 & 0.29 & 0.70 & 0.68 \\
\hline Lying time, $\min / \mathrm{d}$ & 631.7 & 671.8 & 709.9 & 685.2 & 40.8 & 0.23 & 0.84 & 0.39 \\
\hline Lying bouts, no./d & 5.80 & 7.22 & 7.84 & 6.41 & 1.58 & 0.61 & 0.99 & 0.24 \\
\hline Lying bout duration, $\min /$ bout & 68.6 & 59.1 & 60.8 & 69.2 & 6.1 & 0.84 & 0.93 & 0.14 \\
\hline
\end{tabular}

${ }^{1} \mathrm{SEM}$ for the interaction is reported.

${ }^{2}$ Data previously reported in Table 2 but included to provide a complete representation of behavioral responses.

H-FOR PMR, the amount of concentrate offered in the AMS does not affect SCFA concentration. Although other fermentation parameters were not affected by the interaction, the increase in SCFA concentration can be expected because the $\mathrm{F}: \mathrm{C}$ ratio was the least when LFOR was fed with H-AMS (Penner et al., 2009).

The general lack of treatment interactions in this experiment is interesting given the marked changes in the dietary chemical composition, particularly the dietary NDF measured using $\alpha$-amylase and sodium sulfite followed by correction for the ash content and starch. As such, it appears that while considering both the PMR and AMS concentrate are necessary for dietary formulation and that increasing AMS concentrate reduces PMR intake, altering the $\mathrm{F}: \mathrm{C}$ ratio of the PMR and the amount of concentrate in the AMS generally impose effects on production responses and feeding behavior independently.

\section{Effects Arising from Increased AMS Concentrate Allocation}

To date, most studies have focused exclusively on changing the AMS allocation or composition (Halachmi et al., 2005; Migliorati et al., 2005) and only a few have considered that changes to the AMS concentrate may also affect consumption of the PMR (Bach et al., 2007; Hare et al., 2018). Based on survey data, the proportional contribution of the AMS concentrate likely does not exceed $40 \%$ of the total diet (Salfer and Endres, 2014). Thus, ignoring PMR intake when manipulating the AMS concentrate will likely preclude accurate prediction or interpretation of production outcomes. In the present study, the proportional contribution of the AMS concentrate was $7.12 \%$ of the diet (DM basis) for L-AMS and $21.35 \%$ of the diet for H-AMS. Consistent with previous studies in AMS, we observed that increasing the AMS concentrate allocation decreased PMR intake (Bach et al., 2007; Hare et al., 2018). Providing supplemental concentrate to grazing dairy cows has also been reported to reduce pasture DMI (Bargo et al., 2003; Tozer et al., 2004) or forage OM intake (Macoon et al., 2011). In addition, whereas cows fed H-AMS spent more time eating the concentrate in the AMS compared with cows fed L-AMS, PMR eating time $(\mathrm{min} / \mathrm{d})$ was greater for cows offered L-AMS than cows offered H-AMS.

In the present study, when the data from the L-FOR and H-FOR treatments were pooled, every $1 \mathrm{~kg}$ of DM increase in AMS concentrate consumed decreased PMR DMI by $0.83 \mathrm{~kg}$, suggesting that increasing the AMS concentrate allocation may increase nutrient intake (Bargo et al., 2003). However, the substitution response may differ based on $\mathrm{F}$ : $\mathrm{C}$ ratio of the $\mathrm{PMR}$ as the calculated substitution rates were 0.89 when fed the L-FOR PMR and 0.78 when fed the H-FOR PMR. Although we are unable to compare these values statistically, these data indicate that feeding a more energy-dense PMR increases the substitution rate. The difference in substitution rate between the L-FOR and H-FOR PMR supports previous research with grazing cattle where improved forage quality increases the substitution rate (Fieser and Vanzant, 2004).

In contrast to the substitution effects that were less than 1 in the present study, Bach et al. (2007) reported (DM basis) that for every 1-kg increase in AMS concentrate there was a 1.14-kg reduction in PMR consumed and Hare et al. (2018) reported a reduction of $1.58 \mathrm{~kg}$ of PMR intake for every 1-kg increase in AMS concentrate. The differences observed in the substitution rates 
between the present study and previous studies may be due to dietary formulation strategies and physiological state of cattle in the study. For example, Bach et al. (2007) and Hare et al. (2018) attempted to provide isocaloric diets by shifting concentrate from the PMR to the AMS. In the present study, we purposely increased the nutrient density with the H-AMS versus L-AMS and with the L-FOR versus H-FOR treatments. Furthermore, given that the cattle in the present study were in mid-lactation, it is likely that rumen fill was limiting DMI (Allen et al., 2009) and decreasing the $\mathrm{F}$ :C ratio by offering H-AMS may have allowed for numerically greater DMI. Additionally, milk production in the present study was markedly greater than that in Bach et al. (2007) and Hare et al. (2018), suggesting that physiological state or nutrient demand may alter responses to increased dietary energy density. For example, in the present study, cows were in mid-lactation, with an average DIM of $140.5 \pm 13.6$ (mean \pm SD) and $168.5 \pm 9.7$ for the respective squares. Bach et al. (2007) utilized 115 cows in mid-lactation; however, the cows in that study were, on average, $191 \pm 2.1$ DIM and also incorporated production responses from multiparous and primiparous cows. Hare et al. (2018) also combined responses for primiparous and multiparous cows that had lower milk yield than in the present study. Although we cannot determine the cause for the substitution effect in the present study, total PMR eating time and ruminal $\mathrm{pH}$ were not affected by the $\mathrm{F}: \mathrm{C}$ ratio of the PMR, suggesting that factors other than those specified for grazing cows (Bargo et al., 2003) may influence the substitution rate for cows in AMS.

Although previous studies have assessed increasing the AMS concentrate allocation, cows in those studies did not consume their full AMS allocation (Halachmi et al., 2005; Migliorati et al., 2005; Bach et al., 2007). For example, Bach et al. (2007) targeted consumption of 3 or $8 \mathrm{~kg} / \mathrm{d}$ (DM basis) of AMS concentrate, but cows only consumed 2.6 or $6.9 \mathrm{~kg} / \mathrm{d}$ (DM basis), respectively. Halachmi et al. (2005) targeted either $1.2 \mathrm{~kg} /$ visit or $7 \mathrm{~kg} / \mathrm{d}$ but achieved consumption of 3.5 and $5 \mathrm{~kg} / \mathrm{d}$, respectively. In the present study, we ensured that consumption of the AMS concentrate was equal to the target by adjusting the potentially eligible concentrate such that it was in excess of the target. For example, to achieve target AMS concentrate intake, cows fed LAMS were eligible to receive $2.07 \mathrm{~kg}$ of $\mathrm{DM} / \mathrm{d}$ and cows fed $\mathrm{H}$-AMS were eligible to receive $6.55 \mathrm{~kg}$ of $\mathrm{DM} / \mathrm{d}$. As a consequence, feeding a greater quantity of concentrate in the AMS resulted in a greater SD in concentrate intake among days for individual cows. To our knowledge, no previous studies have evaluated the variability in concentrate intake among days as affected by the quantity offered in the AMS. Despite greater variation among days for cows fed H-AMS than L-AMS, cows did not increase their variability for PMR intake regardless of the F:C ratio within the PMR. The greater variability in AMS concentrate intake with increasing AMS provision diminishes the ability to impose precision feeding strategies when using a single pellet. However, precision feeding strategies could also integrate the use of more than one pellet allowing for dietary compositional changes without markedly increasing the amount of pellet offered in the AMS (Bach and Cabrera, 2017). Future research is needed to evaluate the magnitude of variation in AMS concentrate allocation as affected by pellet composition (starch vs. fiber vs. protein), physiological state, and the implications on achieving precision feeding strategies and production outcomes.

Recommendations for AMS feeding management suggest that providing a greater quantity of concentrate within the AMS will increase voluntary visits and milk yield (Rodenburg, 2011). In our study, increasing the amount of AMS concentrate from 2 to $6 \mathrm{~kg}$ (DM basis) did not affect milking frequency, but tended to increase daily milk yield by $1.25 \mathrm{~kg}$. Others have reported that increasing the quantity of concentrate offered in the AMS did not result in improved milking frequency or milk production (Halachmi et al., 2005; Migliorati et al., 2005; Bach et al., 2007; Hare et al., 2018). Even in free-traffic flow conditions, increasing the AMS concentrate allocation was correlated with reduced milk yield (Tremblay et al., 2016). As such, motivation to enter the AMS seems not to be primarily affected by the amount of concentrate offered within the AMS under free-flow cow traffic (Halachmi et al., 2005; Bach et al., 2007; Tremblay et al., 2016) or guided cow traffic (Migliorati et al., 2005; Hare et al., 2018). In addition to the lack of a stimulatory effect on milking frequency with greater concentrate provision, time spent in the holding area before milking was not affected by the amount of concentrate provided in the AMS. This may suggest that increasing the amount of AMS concentrate allocation above $2 \mathrm{~kg} / \mathrm{d}$ may not improve motivation to enter the AMS.

In our study, increasing the AMS concentrate allocation increased dietary energy density, likely accounting for the tendency for increased milk yield despite no changes in milking frequency. In fact, using calculations from NRC (2001), cows fed H-AMS consumed 47.6 Mcal of $\mathrm{NE}_{\mathrm{L}}$ versus $45.0 \mathrm{Mcal}$ of $\mathrm{NE}_{\mathrm{L}}$ (data not shown) consumed by cows fed L-AMS. The studies of Bach et al. (2007) and Hare et al. (2018) fed isocaloric diets when comparing low and high concentrate allocations in the AMS and reported no treatment effect, likely due to the lack of change in predicted energy intake. By increasing the amount of concentrate offered in the AMS, digestibility of $\mathrm{OM}$ and $\mathrm{DM}$ was increased, providing 
further explanation for the trend for greater milk yield for cows fed H-AMS relative to L-AMS. In contrast to our findings, Halachmi et al. (2005) and Migliorati et al. (2005) did not observe an increase in milk yield with increasing concentrate allocation. However, in those studies PMR intake was not reported and hence important information is missing. Moreover, Halachmi et al. (2005) conducted their study encompassing cows varying in DIM but did not report whether production responses differed by DIM nor did they report the proportion of cows by stage of lactation. It could be expected that using cows in late lactation would diminish potential effects for milk yield arising from greater energy density.

Along with a tendency for greater milk yield, milk $\mathrm{CP}$ yield tended to be greater, $\mathrm{CP}$ concentration was greater, and fat concentration tended to be less for $\mathrm{H}$ AMS cows than L-AMS cows. The greater CP concentration for cows fed H-AMS compared with cows under L-AMS treatments is not surprising when considering the greater fermentable energy intake and the expected increase in metabolizable protein supply as previously mentioned (Grant and Kononoff, 2007). Although milk fat concentration tended to be lower for cows fed $\mathrm{H}-$ AMS relative to cows fed L-AMS, the response was likely due to dilution considering that milk fat yield was not affected. Miron et al. (2004) also observed a reduction in milk fat percentage when feeding greater quantities of concentrate in the AMS.

To date, we are unaware of studies characterizing the effect of AMS concentrate allocation on ruminal fermentation. In the current study, we expected to see a reduction in ruminal $\mathrm{pH}$ for cows fed H-AMS relative to cows fed L-AMS; however, we did not observe such a response. The lack of a ruminal $\mathrm{pH}$ response may be partially due to variable AMS concentrate intake among days for cows fed greater quantities of AMS concentrate, variable timing of AMS concentrate provision, altered PMR eating and sorting characteristics, and the relatively small concentrate meals provided in the AMS. In particular, substantial day-to-day variation in AMS concentrate intake may have disguised the direct effect of providing a greater amount of concentrate in the AMS on ruminal $\mathrm{pH}$. In addition to the varying day-to-day AMS concentrate consumption, cows offered H-AMS, on average, visited the robot 3.69 times/d and consumed $1.67 \mathrm{~kg}$ (DM basis) of AMS concentrate/ milking with a maximum of $2.5 \mathrm{~kg} / \mathrm{visit}$, regardless of the AMS concentrate treatment. Thus, small amounts $(<2.5 \mathrm{~kg})$ of concentrate provided in a single meal may simply not have a marked effect on ruminal $\mathrm{pH}$. That said, we cannot eliminate the possibility that PMR eating and sorting characteristics may have also affected the outcome as cows in the present study were required to access the PMR feeding area before entering the selection gate that provided access to the AMS. Thus, the consumption of the PMR and the reduction in selection against particles retained on the 8-mm sieve and a reduction in the selection for particles retained on the 4-mm sieve for cows fed H-AMS versus L-AMS may have modulated the ruminal $\mathrm{pH}$ response (DeVries et al., 2008), independent of the AMS concentrate allocation. Although ruminal $\mathrm{pH}$ was not affected by the amount of concentrate provided in the AMS, an interaction occurred for SCFA concentration where cows fed L-FOR had a greater SCFA concentration while being fed greater quantities of concentrate in the AMS. Although no studies have shown SCFA responses in AMS, this result potentiates the greater energy supply as AMS concentrate increased and may further suggest that fermentation responses were evident. Future research is needed to evaluate ruminal fermentation responses for cows managed in AMS.

\section{Effects Arising from Increased Concentrate Allocation in the PMR}

To our knowledge, no studies have evaluated the effect of different $\mathrm{F}: \mathrm{C}$ ratios within the PMR on performance outcomes for cows milked using AMS. In the present study, the PMR accounted for 92.9 and $78.7 \%$ of the dietary DM for the L-AMS and H-AMS treatments, respectively. Increasing the proportion of concentrate within the PMR from 36 to $46 \%$ tended to increase daily milk yield without changing milking frequency. Hare et al. (2018) reported a tendency for increased milk yield when the PMR contained a greater energy density; however, in that study, the diets were isocaloric. This may suggest that PMR energy density is unlikely to negatively affect milk yield and voluntary visits to the AMS. The greater milk yield response for cows fed L-FOR compared with H-FOR in the present study is likely due to a greater energy supply with a predicted $1 \mathrm{Mcal} / \mathrm{d}$ greater energy intake for cows fed L-FOR. Moreover, feeding L-FOR resulted in greater digestibility of DM and OM compared with H-FOR, further suggesting greater nutrient availability for cows fed L-FOR.

Despite a tendency for greater milk yield, feeding the L-FOR PMR may have reduced the motivation to enter the AMS based on greater time spent in the holding area relative to cows fed a H-FOR. The lack of motivation highlights the potential effect that PMR formulation may have on cow activity budgets and may challenge the use of a L-FOR feeding strategy for cows housed in free-traffic-flow barns. However, the number of visits to the AMS were not reduced when feeding LFOR compared with H-FOR, likely due to the selection 
gate and milking criteria settings in the guided-flow system used in this study. Clearly, more research is needed to assess activity budgets of cows and implications on performance outcomes when altering the PMR energy density and to determine whether recommendations should consider cow traffic flow design.

Altering the $\mathrm{F}: \mathrm{C}$ ratio of the PMR did not affect PMR intake or AMS intake. This suggests that PMR consumption is more affected by the amount of concentrate offered in the AMS than the energy density of the PMR itself. Moreover, the F:C ratio of the PMR did not affect variability in PMR consumption among days. Similar to Hare et al. (2018), we did not observe any changes in PMR eating behavior and only minimal changes in PMR sorting characteristics when altering the PMR F:C ratio. These results suggest that although PMR intake is impaired by the greater amount of concentrate provided in the AMS, PMR eating behavior remains stable regardless of differences within the PMR. That said, both studies were conducted in a guided-flow system, which may also impose differences in eating behavior pattern relative to other barn designs. More research is needed because past studies, such as DeVries et al. (2007), have reported differences in eating behavior when changing the $\mathrm{F}$ : $\mathrm{C}$ ratio; however, previous studies have been conducted with TMR feeding scenarios rather than with PMR.

With respect to ruminal $\mathrm{pH}$, minimum $\mathrm{pH}$ tended to be greater for cows fed H-FOR than L-FOR and the area that $\mathrm{pH}$ was $<5.8$ tended to be greater for cows fed L-FOR than H-FOR. The response in ruminal $\mathrm{pH}$ is not surprising given the greater proportion of concentrate in the PMR and greater digestibility. In addition, the reduction in the proportion of acetate and increase in propionate concentrations observed in this study are consistent with a decreased $\mathrm{F}$ : $\mathrm{C}$ ratio diets (Kljak et al., 2017).

Whereas numerous studies have evaluated the $\mathrm{F}$ :C ratio of the TMR on performance outcomes for dairy cows (Voelker et al., 2002; Mäntysaari et al., 2003; Kargar et al., 2010), no studies have provided such information for cows using AMS. This research is needed because altering the PMR has been previously suggested to affect the AMS concentrate feeding strategy. In a recent study, Tremblay et al. (2016) suggested that the use of a PMR with a high F:C ratio or a PMR with low forage quality would likely require the provision of greater quantities of concentrate in the AMS. In fact, the authors of that study rationalized that low-quality forages, in particular, would require greater AMS concentrate provision and that under such situations, AMS concentrate provision was negatively correlated with milk production. However, no information was provided on PMR composition or PMR intake in that study. Results from the present study suggest that the PMR and AMS concentrate allocation independently affect production responses, thereby providing further justification that the PMR composition and intake must be considered.

\section{CONCLUSIONS}

The data in the present study are interpreted to suggest that the $\mathrm{F}: \mathrm{C}$ ratio of the PMR and the quantity of concentrate offered in the AMS act independently on performance outcomes. Our results indicate that the quantity of AMS concentrate offered reduces PMR intake with only marginal effects on milk and milk component yield, but feeding a greater amount of concentrate in the AMS increases day-to-day variability in AMS concentrate consumption, challenging the notion of precision feeding when simply increasing the amount of pellets offered in the AMS. In addition, providing a greater proportion of concentrate in the PMR may improve milk yield without increasing variability in PMR or AMS concentrate intake, but may result in reduced ruminal $\mathrm{pH}$.

\section{ACKNOWLEDGMENTS}

We thank the Alberta Livestock and Meat Agency Ltd. (Edmonton, AB), Saskatchewan Ministry of Agriculture (Regina, SK), the Dairy Farmers of Manitoba (Winnipeg, MB), Saskmilk (Regina, SK), and Alberta Milk (Edmonton, AB) for providing funding for this project.

\section{REFERENCES}

Allen, M. S., B. J. Bradford, and M. Oba. 2009. The hepatic oxidation theory of the control of feed intake and its application to ruminants. J. Anim. Sci. 87:3317-3334. https://doi.org/10.2527/ jas.2009-1779.

Bach, A., and V. Cabrera. 2017. Robotic milking: Feeding strategies and economic returns. J. Dairy Sci. 100:7720-7728.

Bach, A., C. Iglesias, S. Calsamiglia, and M. Devant. 2007. Effect of amount of concentrate offered in Automatic Milking Systems on milking frequency, feeding behavior, and milk production of dairy cattle consuming high amounts of corn silage. J. Dairy Sci. 90:5049-5055.

Bargo, F., L. D. Muller, E. S. Kolver, and J. E. Delahoy. 2003. Invited Review: Production and digestion of supplemented dairy cows on pasture. J. Dairy Sci. 86:1-42.

Bava, L., A. Tamburini, C. Penati, E. Riva, G. Mattachini, G. Provolo, and A. Sandrucci. 2012. Effects of feeding frequency and environmental conditions on dry matter intake, milk yield and behaviour of dairy cows milked in conventional or automatic milking systems. Ital. J. Anim. Sci. 11:230-235.

Chapinal, N., D. M. Veira, D. M. Weary, and M. A. G. von Keyserlingk. 2007. Technical note: Validation of a system for monitoring individual feeding and drinking behavior and intake in group housed dairy cows. J. Dairy Sci. 90:5732-5736. 
DeVries, T. J., K. A. Beauchemin, and M. A. G. von Keyserlingk. 2007. Dietary forage concentration affects the feed sorting behavior of lactating dairy cows. J. Dairy Sci. 90:5572-5579.

DeVries, T. J., F. Dohme, and K. A. Beauchemin. 2008. Repeated ruminal acidosis challenges in lactating dairy cows at high and low risk for developing acidosis: Feed sorting. J. Dairy Sci. 91:39583967.

DeVries, T. J., M. A. G. von Keyserslingk, D. M. Weary, and K. A. Beauchemin. 2003. Measuring the feeding behavior of lactating dairy cows in early to peak lactation. J. Dairy Sci. 86:3354-3361.

Fawcett, J. K., and J. E. Scott. 1960. A rapid and precise method for the determination of urea. J. Clin. Pathol. 13:156-159.

Fieser, B. G., and E. S. Vanzant. 2004. Interactions between supplement energy source and tall fescue hay maturity on forage utilization by beef steers. J. Anim. Sci. 82:307-318.

Grant, R., and P. J. Kononoff. 2007. Feeding to maximize milk protein and fat yields. University of Nebraska-Lincoln Extension, Institute of Agriculture and Natural Resources. Accessed Feb. 7, 2018. http: //extensionpublications.unl.edu/assets/pdf/g1358.pdf.

Halachmi, I. S. Ofir, and J. Miron. 2005. Comparing two concentrate allowances in an automatic milking system. Anim. Sci. 80:339-343.

Hare, K., T. J. DeVries, K. S. Schwartzkopf-Genswein, and G. B. Penner. 2018. Short communication: Does the location of concentrate provision affect voluntary visits, and milk and milk component yield for cows in an automated milking system. Can. J. Anim. Sci. 98:399-404.

Huhtanen, P., K. Kaustell, and S. Jaakkola. 1994. The use of internal markers to predict total digestibility and duodenal flow of nutrients in cattle given six different diets. Anim. Feed Sci. Technol. 48:211-227.

Kargar, S., M. Khorvash, G. R. Ghorbani, M. Alikhani, and W. Z. Yang. 2010. Short communication: Effect of dietary fat supplements and forage:concentrate ratio on feed intake, feeding, and chewing behavior of Holstein dairy cows. J. Dairy Sci. 93:42974301.

Khorasani, G. R., E. K. Okine, and J. J. Kennelly. 1996. Forage source alters nutrient supply to the intestine without influencing milk yield. J. Dairy Sci. 79:862-872.

Kljak, K., F. Pino, and A. J. Heinrichs. 2017. Effect of forage to concentrate ratio with sorghum silage as a source of forage on rumen fermentation, $\mathrm{N}$ balance, and purine derivative excretion in limitfed dairy heifers. J. Dairy Sci. 100:213-223.

Kononoff, P. J., A. J. Heinrichs, and D. R. Buckmaster. 2003. Modification of the Penn State Forage and Total Mixed Ration Particle Size Separator and the effects of moisture content on its measurements. J. Dairy Sci. 86:1858-1863.

Ledgerwood, D. N., C. Winckler, and C. B. Tucker. 2010. Evaluation of data loggers, sampling intervals, and editing techniques for measuring the lying behavior of dairy cattle. J. Dairy Sci. 93:5129-5139.

Leonardi, C., and L. E. Armentano. 2003. Effect of quantity, quality, and length of alfalfa hay on selective consumption by dairy cows. J. Dairy Sci. 86:557-564.

Macoon, B., L. E. Sollenberger, C. R. Staples, K. M. Portier, J. H. Fike, and J. E. Moore. 2011. Grazing management and supplementation effects on forage and dairy cow performance on cool-season pastures in southeastern United States. J. Dairy Sci. 94:3949-3959.

Mäntysaari, P., J. Nousiainen, and P. Huhtanen. 2003. The effect of constant or variable forage to concentrate ratio in total mixed ration on performance of primiparous dairy cows. Livest. Sci $82: 27-37$.

Maulfair, D. D., M. Fustini, and A. J. Heinrichs. 2011. Effect of varying total mixed ration particle size on rumen digesta and fecal particle size and digestibility in lactating dairy cows. J. Dairy Sci. 94:3527-3536.

Melin, M., K. Svennersten-Sjaunja, and H. Wiktorsson. 2005. Feeding patterns and performance of cows in controlled cow traffic in automatic milking systems. J. Dairy Sci. 88:3913-3922.

Migliorati, L., M. Speroni, S. Lolli, and F. Calza. 2005. Effect of concentrate feeding on milking frequency and milk yield in an automatic milking system. Ital. J. Anim. Sci. 4:221-223.

Miron, J., E. Yosef, M. Nikbachat, A. Zenou, E. Maltz, I. Halachmi, and D. Ben-Ghedalia. 2004. Feeding behavior and performance of dairy cows fed pelleted nonroughage fiber byproducts. J. Dairy Sci. 87:1372-1379.

NRC. 2001. Nutrient Requirements of Dairy Cattle. 7th rev. ed. Natl. Acad. Sci., Washington, DC.

Penner, G. B., K. A. Beauchemin, and T. Mutsvangwa. 2006. An evaluation of the accuracy and precision of a stand-alone submersible continuous ruminal $\mathrm{pH}$ measurement system. J. Dairy Sci. $89: 2132-2140$

Penner, G. B., K. A. Beauchemin, and T. Mutsvangwa. 2007. Severity of ruminal acidosis in primiparous Holstein cows during the periparturient period. J. Dairy Sci. 90:365-375.

Penner, G. B., M. Taniguchi, L. L. Guan, K. A. Beauchemin, and M. Oba. 2009. Effect of dietary forage to concentrate ratio on volatile fatty acid absorption and the expression of genes related to volatile fatty acid absorption and metabolism in ruminal tissue. J. Dairy Sci. 92:2767-2781.

Prescott, N. B., T. T. Mottram, and A. J. F. Webster. 1998. Relative motivations of dairy cows to be milked or fed in a Y-maze and an automatic milking system. Appl. Anim. Behav. Sci. 57:23-33.

Rodenburg, J. 2011. Designing feeding systems for robotic milking. Pages 127-136 in Proc. Tri-State Dairy Nutrition Conference, Ft. Wayne, IN. Accessed Sep. 2, 2018. https://docs.wixstatic.com/ ugd/36a444_c799a95d7ce041b2944e67c69e08cd91.pdf.

Salfer, J., and M. Endres. 2014. How are robotic milking dairies feeding their cows? Pages 77-80 in Proc. 4-State Dairy Nutrition \& Management Conference. Dubuque, IA.

Tozer, P. R., F. Bargo, and L. D. Muller. 2004. The effect of pasture allowance and supplementation on feed efficiency and profitability of dairy systems. J. Dairy Sci. 87:2902-2911.

Tremblay, M., J. P. Hess, B. M. Christenson, K. K. Mclntyre, B. Smink, A. J. van der Kamp, L. G. de Jong, and D. Döpfer. 2016. Factors associated with increased milk production for automatic milking systems. J. Dairy Sci. 99:3824-3837.

Voelker, J. A., G. M. Burato, and M. S. Allen. 2002. Effects of pretrial milk yield on responses of feed intake, digestion, and production to dietary forage concentration. J. Dairy Sci. 85:2650-2661.

Wildman, E. E., I. G. M. Jones, P. E. Wagner, and R. L. Boman. 1982. A dairy cow body condition scoring system and its relationship to selected production characteristics. J. Dairy Sci. 65:495-501.

Zobel. G., and N. Chapinal. 2013. UBC Animal Welfare Program: SOP - HOBO Data Loggers. pp. 1-23. University of British Columbia, Vancouver, Canada. 